\title{
COMPOUND FRACTURE OF THE FEMUR
}

\author{
TWENTY YEARS AFTER EXCISION OF THE KNEE- \\ JOINT FOR DISEASE,
}

THE LINE OF FRACTURE BEING TRANSVERSELY

ONE INCH ABOVE THE BONY UNION.

BY

FREDERICK JAMES GANT, F.R.C.S., SENIOR SURGEON TO THE ROYAL FREE HOSPITAL.

(Received February 12th-Read April 27th, 1880.)

ThE previous history of this case is included in a series of joint-excisions which I brought before the Society in the year 1870, and which is published in the 'Transactions,' vol. liii ; but it may not be uninteresting to briefly relate the chief particulars of the case in connection with its sequel.

Elizabeth D-, æt. 33, married, without children, had always enjoyed good health. In the year 1853 she injured her right knee, by a wrench inwards, from a fall, which was followed by the swelling and pain of acute synovitis. Treatment seems to have had little permanent effect, for the disease continued in a chronic form. Five years afterwards a rheumatic attack, apparently, affected the same joint. September, 1859, she was admitted into the Royal Free Hospital. The joint was then considerably swollen, and discharging through three sinuses a thin 
purulent matter. Grating crepitus and mobility plainly declared that destruction of the articular cartilages had occurred, with-as the operation showed-deeper caries of the adjoining portions of the femur and tibia than is usual in consequence of synovitis, especially of traumatic origin, and the leg being drawn backwards toward the buttock the limb was rendered further useless. The constitutional condition was that of nervous exhaustion from six years' uninterrupted suffering, the patient having obtained snatches of sleep at night by pouring a pitcherful of cold water over the knee, to kill the pain, as she said, in the hope of dosing off before it returned. But there was no hectic nor marked emaciation.

Under these circumstances I excised the joint, and then fixed the limb in a McIntyre splint, an apparatus which I have long since discarded for the back-splint, and interrupted external splint with foot-piece, as constructed for subsequent cases. After operation, the patient's health rapidly improved, and the wound, with simply lintdressing, healed by primary union, except at the external angle, where healthy granulations sprang up. At the end of a month, the splint was removed for the purpose of cleanliness. In two months, a shorter period than usual by at least a month, after excision of the knee-joint, the splint was finally removed. So firm had osseous union become that the patient was then allowed to move about on crutches, with the leg bandaged only to prevent swelling. The limb remained perfectly straight, and a high-heeled shoe enabled the woman to walk with a carriage quite easy and symmetrical. She often walked distances of four, six, and eight miles a day, without any inconvenience. This result I had the opportunity of ascertaining during the first ten years before the case appeared, as figured Plate I, fig. 1, in the volume of the 'Transactions' referred to.

Ten years subsequently, E. D- slipped downstairs, and doubled the right leg under her. The integument was torn across, above the situation of the knee, to the 
extent of six inches, and the femur snapped. Considerable hæmorrhage occurred, but the popliteal artery escaped injury. When brought to the hospital the patient lay in a wandering state of collapse and shock, from which she never rallied. Post-mortem examination revealed extensive changes in various organs, but the

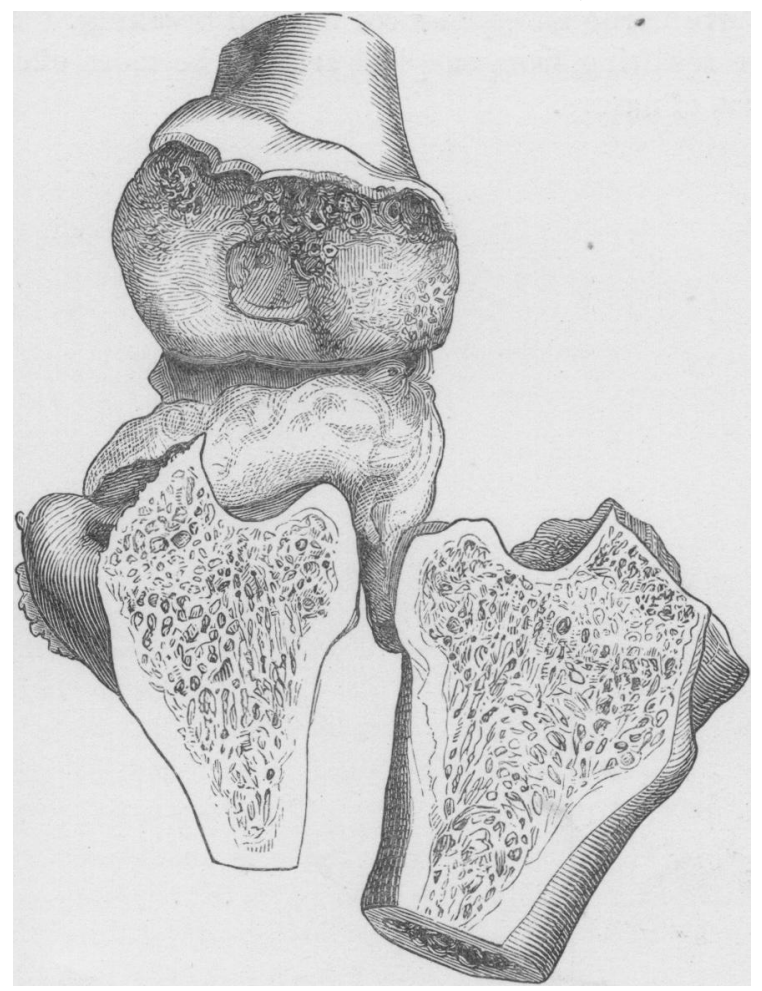

surgical interest in this case centres in the coexisting synostosis and adjoining fracture to which $I$ have drawn attention. The specimen is here represented. Section shows the complete character of the synostosis, the osseous texture of the femur and tibia having become so fused together that the junction is imperceptible, being indicated vol. LXIII. 
only by a transverse line in the cancellated structure, between the tibia and the femoral fragment, as represented in the figure. The strength of this union is attested by its having withstood the extreme violence, coupled with the long leverage of the leg, that produced a compound fracture through the bulky end of the femur. It is very doubtful whether an ossific anchylosis of the knee-joint would have borne an equal force without breaking. Thus, the cure resulting from surgical art may be more effectual than that of nature. 